\title{
Brasil e Portugal: a história nacional entre tradição e renovação
}

Brazil and Portugal: the national

History between Tradition and

Renewal

\section{Ana Lúcia Lana Nemi}

Professora no Departamento de História da Universidade Federal de São Paulo

\section{Resumo}

Este pequeno ensaio tem por objetivo estudar a representação da nação no pensamento das elites intelectuais ibéricas da virada do século XIX para o XX discutindo a visão de "decadência" do Império colonial, construído a partir dos séculos XV/XVI, e a percepção do "atraso" em relação às potências centrais do capitalismo. Para tanto, destaquei o debate em torno da decadência ibérica e das possibilidades de organização de um novo império português na África no contexto da ação pública da chamada geração de 70.

\begin{abstract}
This assay aims to study the representation of the Nation according to the formulations of the lberian intellectual elites in the end of the $19^{\text {th }}$ century and beginning of the $20^{\text {th }}$ century. It discusses the idea of the Colonial Empire decadence, as constructed in the $15^{\text {th }}$ and $16^{\text {th }}$ centuries, and the perception of a setback in reference to the central powers of capitalism. In order to do that it focuses on the debate concerning the lberian decadence and the chances of organizing a new Portuguese Empire in Africa, in the context of the public action of the so-called Generation of 70 .
\end{abstract}

\section{Palavras-chave}

elites, nação, liberalismo, modernização, América portuguesa / Brasil

\section{Keywords}

elites, nation, liberalism, modernization, Portuguese America / Brazil 
Sérgio B. de HOLANDA. "Prefácio", In: Visão do Paraíso. S. P., Brasiliense,1996, p. XVIII.

2

António Manuel B. Machado PIRES, A idéia de decadência na geração de 70, Ponta Delgada: Instituto Universitário dos Açores, 1980. Maria Aparecida Rezende MOTA, Brasil e Portugal: imagens da nação na geração de 70 do sécuIo XIX, Tese de Doutorado, IFCS/UFRJ, 1998, policopiado.

3

Este ensaio é resultado das pesquisas que envolvem a execução do projeto de pós-doc subvencionado pela Fapesp "Virando o século: os intelectuais e a política no Mundo Ibérico (1870-1939)". 0 estudo envolve elites intelectuais do Brasil, Portugal e Espanha.

Antero de QUENTAL, Causas da decadência dos povos peninsulares, Lisboa: Ulmeiro, 1987 (Texto lido pela primeira vez em 1871, nas Conferências do Casino de Lisboa). Teófilo BRAGA, Soluções positivas da política portuguesa, Porto: Livraria Chardron de Lello \& Irmão, 1913 (Primeira edição: 1879). Sobre o binômio decadência/regeneração em Antero cabe citar o interessante trabalho de André Nunes de AZEVEDO, "As idéias de decadência e regeneração no ideário político de Antero de Quental", In: Revista Intellectus, Ano IV, Volume I, 2005, além de Fernando CATR0GA, Antero de Quental - história, socialismo e política, Lisboa: Editorial Notícias, 2001. Sobre Teófilo cabe citar Amadeu Carvalho HOMEM, A idéia republicano em Portugal -- o contributo de Teófilo Braga, Coimbra: Minerva, 1989

Sérgio Campos MATOS, Historiografia e memória nacional no Portugal do século XIX, Lisboa: Colibri, 1998.
"Ao lado da interação da base material e da estrutura ideológica, e como decorrência dela, não falta quem aponte para a circunstância de que, sendo as idéias fruto de modos de produção ocorridos em determinada sociedade, bem podem deslocar-se para outras áreas onde não preexistam condições perfeitamente idênticas, e então lhes sucederá anteciparem nelas, e estimularem, os processos materiais de mudança social. Ora, assim como essas idéias se movem no espaço, há de acontecer que também viajem no tempo, e porventura mais depressa do que os suportes, passando a reagir sobre condições diferentes que venham a encontrar ao longo do caminho. $O$ tema deste livro é a biografia de uma dessas idéias migratórias, tal como se desenvolveu a partir das origens religiosas ou míticas, (...) até vir implantar-se no espaço latino-americano, mormente no Brasil".

(Sérgio Buarque de Holanda) ${ }^{1}$

Este pequeno ensaio tem por objetivo estudar a representação da nação no pensamento das elites intelectuais ibéricas da virada do século XIX para o XX discutindo a visão de "decadência" do Império colonial ${ }^{2}$, construido a partir dos séculos $X V / X V I$, e a percepção do "atraso" em relação às potências centrais do capitalismo. ${ }^{3}$ Para tanto, destaquei o debate em torno da decadência ibérica e das possibilidades de organização de um novo império português na África no contexto da ação pública da chamada geração de 70.

\section{Antero de Quental e Teófilo Braga: a História nacional entre tradição e renovação.}

Os textos Causas da decadência dos povos peninsulares, de Antero de Quental, e Soluções positivas da política portuguesa ${ }^{4}$, de Teófilo Braga, são fundamentais para a compreensão do debate sobre as possibilidades de modernização e/ou regeneração das nações ibéricas, destacados aqui Portugal e Brasil, no século XIX. Os dois autores, expoentes da chamada geração de 70 portuguesa, fundamentam sua argumentação na abordagem do Império, o primeiro buscando esquadrinhar seus significados e conseqüências e o segundo mais marcado pela possibilidade regeneracionista posto que, enquanto representante do republicanismo de corte positivista emblemado no Partido Republicano Português, advogava a regeneração da nação pela revolução republicana e pela retomada e efetivação do projeto colonialista africano. Neste ponto, assinale-se, há diferenças que apontaram caminhos políticos e institucionais controversos tanto entre intelectuais e políticos coevos como na historiografia.

Antero e Teófilo são homens de cultura tributários da experiência intelectual das elites vintistas ${ }^{5}$, preocupadas em preservar a história nacional diante do turbilhão que invadira a península em 1808. Os dois autores constroem uma versão nacional para o liberalismo cuja legitimidade ancorase em um certo sentido de continuidade da história-pátria e encontra, dessa forma, seu enraizamento no próprio mundo ibérico. Suas reflexões enfrentam o tema da decadência, mas trazem, para além das marcas daquele primeiro liberalismo português, marcas da experiência de 1848 quando, para muitos, evidenciou-se o fracasso do liberalismo na instauração da liberdade e da fraternidade propugnadas desde 1789. Trazem, ainda, as marcas das experiências francesa e espanhola de 1870-1871, 
6

Assinaram o programa/manifesto Adolfo

Coelho, Antero de Quental, Augusto Soromenho, Augusto Fuschini, Eça de Queiroz, Germano Vieira Meireles, Guilherme de Azevedo, Jaime Batalha Reis, J. P. Oliveira Martins, Manuel de Arriaga, Salomão Sáragga e Teófilo Braga.

Citado por João MEDINA, As conferências do Casino e o socialismo em Portugal, Lisboa: Publicações dom Quixote, 1984, pp. 70-71.

8

Sérgio Campos MATOS, ob. Cit., p. 351.

Vitorino M. GODINHO, Mito e mercadoria, utopia e prática de navegar, Lisboa: Difel, 1990.

10

A última das sete páginas que compunham $A$ Berlinda, mais especificamente a de Julho de 1871, periódico que conferiu reconhecimento às intenções de Rafael Bordalo Pinheiro de colocar seu pais na berlinda desenhando opiniões em forma de bandas, dá conta do fechamento das Conferências Democráticas do Casino lisbonense afirmando a "purulenta e burguesa physionomia do paiz, -- esta sua cathólica e monárchica situação" na qual ensino, moral, governo, clero, nobreza, povo e finanças encontram-se em estado lázaro e de corrupção. Os representantes da civilização, os conferencistas, teriam tido a "visão redemptora e de endireita" e foram, exatamente por isso, calados, amordaçados e abafados. Cf.: A Berlinda, Reproducções de um Álbum Humorístico ao correr do lápis, Lisboa: s.l., 1870-1871, digitalizado no Museu Rafael Bordalo Pinheiro de Lisboa. Cf. também: João MEDINA, "Rafael Bordalo Pinheiro: repórter das Conferências do Casino", IN: Eça de Queiroz e a geração de 70, Lisboa: Moraes, 1980, p. 155-161, e Bordalo n'A Berlinda: Mostra Documental 13 de outubro de 2005 a 07 de Janeiro de 2006, Biblioteca Nacional; Coordenação Divisão de Actividade Cultural e Científica: org. e pesquisa: João Paulo Cotrim, Manuela Rego, Lisboa: BN, 2005. tentativas derrotadas de Repúblicas que pretendiam ir além das propostas liberais e acrescentar sentido social aos novos governos.

0 principal debate geracional do 70 português versou sobre o significado do Império na construção e na decadência de Portugal. É dentro das possibilidades encetadas por essa polêmica que se podem compreender os conteúdos do republicanismo e do liberalismo português que, juntamente com a geração de 70, mostram-se a público mais efetivamente a partir das Conferências do Casino Lisbonense de 1871. As intenções dos casinistas que assinaram 6 o programa divulgado em A Revolução de Setembro de 18-V1871 podem ser sumariadas em alguns trechos do programa:

"Ninguém desconhece que se está dando em volta de nós uma transformação política, e todos pressentem que se agita, mais forte que nunca, a questão de saber como deve regenerar-se a organização social.

(...) Pareceu que cumpria, enquanto os povos lutam nas revoluções, e antes que nós mesmos tomemos nelas o nosso lugar, estudar serenamente a significação dessas idéias e a legitimidade desses interesses; investigar como a sociedade é, e como ela deve ser; como as nações têm sido, e como as pode fazer a liberdade; e, por serem elas as formadoras do homem, estudar todas as idéias e todas as correntes do século.

Não pode viver e desenvolver-se um povo, isolado das grandes preocupações intelectuais de seu tempo; o que todos os dias a humanidade vai trabalhando, deve também ser o assunto das nossas constantes meditações."7

0 sentido europeizante das intenções manifestas na proposta, aliado à busca de significado para história nacional, vinha imbricado àquele desejo manifestado já pelo primeiro liberalismo português de inventariar e compreender a história nacional. Havia, ainda, forte "desvalorização do presente que se vivia em meados do século XIX por oposição a uma idade de ouro (fosse ela a Idade Média ou o período dos descobrimentos), que motivava a procura das raízes históricas" 8 da decadência. 0 tema não era novidade entre as elites intelectuais ibéricas. Vitorino Magalhães Godinho indica que a problemática do declínio já aparecia em meados do século XVI, quando se manifestou o debate sobre se a decadência devia-se ao fato de o comércio ter sido substituído pelas conquistas ou se, ao contrário, fora o mercadejar, desenvolvido pelos descobrimentos, que arruinara o caráter nacional tornando a cobiça seu principal traço distintivo. ${ }^{9}$ Por conta da presença desse tema da decadência nacional nos debates decimonônicos, e não tanto pelo fechamento do Casino ${ }^{10}$ após o segundo dia por ordem do governo da Regeneração, que o texto de Antero acima citado galvanizou as discussões das Conferências Democráticas do Casino Lisbonense de 1871. 0 diagnóstico de Antero acerca das causas da decadência dos povos peninsulares apontava para fenômenos da primeira modernidade ibérica:

"Examinemos os fenômenos, que se deram na península durante o decurso do século XVI, período de transição entre a Idade Média e os tempos modernos, e em que aprecem os germens, bons e maus, que mais tarde, desenvolvendo-se nas sociedades modernas, deram a cada qual o seu verdadeiro caráter. (...)

Ora esses fenômenos capitais são três, e de três espécies: um moral, outro político, outro económico. 0 primeiro é a transformação do catolicismo, pelo concilio de Trento. 0 segundo o estabelecimento do absolu- 
Antero de QUENTAL, ob. Cit., p. 29-30.

12

António Manuel HESPANHA, "A História na cultura portuguesa contemporânea", In: Panorama da Cultura Portuguesa no Século XX, Porto: Fundação Serralves, 2002.
13

Cabe aqui uma importante observação acerca dos posicionamentos políticos e ideológicos desses intelectuais ditos de 1870, no Brasil, Portugal ou Espanha. Embora todos tenham dialogado com as teses liberais, positivistas, democráticas e socialistas, no que diz respeito à política, e com as teses realista, naturalista e romântica, especificamente no que tange à literatura, é muito difícil enquadrá-los, individualmente ou em grupo, em qualquer dessas "tendências". Parece mais profícuo, no sentido de melhor compreender o pensamento das elites intelectuais aqui estudadas, afirmá-las como ecléticas, o que, de resto, é comum ao pensamento ocidental no último quartel do século XIX e no primeiro do XX.

14

Teófilo BRAGA, Soluções positivas da política portuguesa, ob. Cit., p. 73. tismo, pela ruína das liberdades locais. 0 terceiro, o desenvolvimento das conquistas longínquas."11

Antero tem os olhos voltados para dois vetores: a história peninsular, cuja experiência cabia retomar para encontrar o caminho da modernização, e a história dos países adiantados da Europa, cuja experiência era preciso trazer para o mundo ibérico. ${ }^{12} 0$ caminho da regeneração passava, assim, pela crítica ao Concilio de Trento que, ao recusar o espírito da modernidade, inviabilizara a vivência da liberdade moral; pela crítica ao absolutismo, que sobrepôs às liberdades medievais a centralização excessiva e inviabilizou a formação de uma classe média industriosa; e pela crítica às conquistas que, incentivando o espírito guerreiro, fundamentara uma mentalidade avessa ao trabalho e a indústria. Organizador de leituras coletivas dos textos de Proudhon no Cenáculo, Antero deixava evidente na sua conferência a marca da proposta federalista e aliava a esta tese elementos da história peninsular: era preciso retomar a experiência medieval de liberdade das cidades que o Absolutismo enterrara. 0 diagnóstico anteriano ecoa a interpretação de Alexandre Herculano que via no Absolutismo, anulador da nobreza e dos municípios, e na expansão ultramarina, que teria corrompido o caráter peninsular, as causas da decadência. 0 autor sintetiza uma experiência intelectual originalmente liberal, vinculada a teses regeneracionistas que propunha um novo desenvolvimento das antigas instituições medievais, era anticlericalista, antiabsolutista e buscava valorizar a presença do povo na História. Na pena de Antero tal proposta ganhou um cunho social de corte proudhoniano e aproximou-se irreversivelmente do republicanismo: é na síntese de Antero, excetuando-se sua crítica à expansão maritima, que o republicanismo português encontra os seus principais motes políticos.

Nesse momento vinha o republicanismo imbricado da idéia nova que poderia redimir a nação: o socialismo manifestado por Antero e Oliveira Martins ${ }^{13}$. Mas havia a proposta do republicanismo com bases positivistas: Teófilo Braga foi seu maior representante nos debates que se seguiram ao Casino e que levaram à fundação do Partido Republicano Português em 1876. Para ele, havia que desafricanizar e europeizar Portugal, em uma palavra havia que modernizar a nação para redimi-la do atraso e da decadência. Neste ponto o republicanismo socialista de Antero aproximava-se do republicanismo positivista de Teófilo. Em 1879, afirmando ser o republicanismo um movimento de continuidade em relação ao vintismo e ao setembrismo e de oposição ao liberalismo cartista, Teófilo assinalava que:

"A monarchia bragantina, interessada na posse incondicional da soberania, e sendo herdeira d'este feudo, de que nós todos como semoventes fazemos parte, dando-nos o nome de súbditos nos seus documentos afficiaes, essa monarchia eshausta e que nos eshaure, é que se tem furtado sempre à revisão da Carta Constitucional por meio de uma côrtes constituintes. Agora já é tarde, já se não póde bolir no edifício sem elle vir à terra de uma vez, no dia em que um parlamento serio discutir a soberania hereditária dá dois pontapés n'este castelo de cartas. Só existe uma soberania effectiva, é a da nação; (...)" 14

Mas Teófilo era representante de uma vertente do republicanismo que buscava a institucionalização da ação dos intelectuais principalmente por meio do PRP. 0 Partido teve forte atuação nos anos 80 e 90 do século 
Joel SERRÃO, Do sebastianismo ao socialismo em Portugal, Lisboa: Horizonte, 1969.

16

Teófilo BRAGA, Contos tradicionais do povo português, Lisboa: Publicações D. Quixote, 1995 e $O$ povo português, Lisboa: Publicações D. Quixote, 1985-6.

17

Vale destacar as comemorações dos centenários de Camões em 1880 e do marquês de Pombal em 1882.

18

Valentim ALEXANDRE, "A politica colonial em finais do Oitocentos: Portugal e a sacralização do Império", In: Velho Brasil, novas Áfricas - Portugal e o Império (1808-1975), Porto: Afrontamento, 2000, pp. 147-162.

19

Fernando CATROGA, 0 republicanismo em Portugal - Da formação ao 5 de outubro de 1910, Coimbra: Faculdade de Letras, 1991. Nuno Severiano TEIXEIRA e António da Costa PINTO (Coords.) A primeira república portuguesa entre o liberalismo e o autoritarismo, Lisboa: Colibri, 2000.

\section{0}

Joel SERRÃO, Liberalismo, socialismo, republicanismo - antologia do pensamento político português, Lisboa: Horizonte, 1979.

\section{1}

João MEDINA, Eça, Antero e Vitor Hugo, Lisboa: Centro de história da Universidade de Lisboa, 2001.
XIX, assim como na primeira década do século XX, no sentido de educar as camadas populares e encontrar os caminhos políticos para a revolução republicana. ${ }^{15}$ Ao lado dessa intensa luta pela popularização do movimento, o que incluiu uma forte aproximação dos movimentos operários organizados, havia a intenção de refletir sobre a história nacional e inventariar suas tradições, contos, caracteristicas e modos de ser, para fundamentar a regeneração do caráter nacional. ${ }^{16}$

$\mathrm{Na}$ esteira da onda conservadora que varreu a Europa pós 1848 e 1871, o PRP canalizou os movimentos populares que cresciam e, por meio das comemorações cívicas que patrocinava e dos grêmios políticos que fundava17, acabou por fortalecer um movimento de sacralização ${ }^{18}$ da memória nacional emblemada na imagem do Império como condição precipua para a preservação do caráter nacional que se pretendia regenerar. Os acontecimentos de 1890 e a repercussão do Ultimatum inglês acirraram uma atitude desse republicanismo institucional que buscava na memória do Império argumentos para criticar a Monarquia e sugerir, às expensas das advertências de Oliveira Martins, a construção de "novos brasis em África". A inflexão conservadora do discurso de Teófilo Braga é evidente: esse republicanismo que se fortalece após 1890, e que será aquele que irá liderar o processo que levou à fundação da República em 1910, dirige-se ao povo genericamente e esvazia os conteúdos possiveis da nação soberana, embora ainda pretenda instaurar o voto universal e acabar com os caciquismos eleitorais de que era constantemente vítima ${ }^{19}$. Afastado do socialismo que se fortalecera com os debates casinistas da geração de 70, esse republicanismo traz em si fortes antinomias: pretende reforçar o colonialismo, que é um fator de tradição, e, também, instaurar a democracia e renovar as instituições políticas. Para Teófilo não há aqui qualquer contradição, posto que, no seu entender, a nação movimenta-se para o futuro em solidariedade com o passado. Mas na prática a sua busca pelo "povo" e pelo "popular" trazia aquele traço tão característico do pensamento conservador do século XIX que via na modernidade e nos seus produtos urbanos e tecnológicos fontes de corrupção das comunidades rurais e de desordem social. Não por acaso será esse nacionalismo tradicionalista do PRP que irá fundamentar a ditadura de Salazar. ${ }^{20}$ Antonio Sardinha, representante do integralismo luso, afirmava, em tom de elogio, que Teófilo era o "mestre da contra-revolução".

Assim, enquanto os republicanos socialistas ligados a Antero de Quental advogavam o internacionalismo político e buscavam superar a imagem criada por Rafael Bordalo Pinheiro do "Zé Povinho" que, analfabeto e apático que era, estava sempre sujeito às ingerências da elite de barões cujo liberalismo era apenas verniz ${ }^{21}$, os republicanos ligados a Teófilo Braga dirigiam-se ao povo e resumiam seu discurso à destruição da Monarquia e a conseqüente fundação da República e do Terceiro Império como condição da regeneração nacional. 0 distanciamento dos dois participantes dos debates do Casino era evidente: na interpretação dos socialistas, e mesmo de Eça de Queiroz e Basilio Telles, tal republicanismo, ancorado em tradicionalismos, não poderia indicar o caminho da refundação nacional.

Para alguns autores, como João Medina, a encruzilhada ideológica que separou Antero e Teófilo e aproximou este autor do que viria a ser o integralismo luso na primeira década do século XX, localiza-se na bifurcação que dividiu os casinistas de 1871 com a fundação do Partido Socialista em 1875 e do Partido Republicano Português em 1876. Este último passou a dedicar-se a tarefas públicas de arregimentação popular e de instituciona- 
22

Rui RAMOS, "0 fim do século", In: José MATTOSO (dir.), História de Portugal - A segunda fundação, Lisboa: Estampa, 1990, vol. 6.

23

IDEM, p. 65.

24

Beatriz BERRINI, Brasil e Portugal: a Geração de 70, Porto: Campo das Letras, 2003.

25

Eça de QUEIROZ, "Os Maias", In: Obras de Eça de Queiroz, Porto: Lello \& Irmão Editores, s/d, vol. II. Neste romance de 1888 Eça resumiu 0 sentimento de derrota dos setentistas vinculados às teses socialistas por meio do personagem $X X X$ que afirmava, ao final do volume "Falhamos à vida, menino" (p. 494). Era o sentimento de um grupo de homens de cultura que legara livros e sonhos aos portugueses, mas que não pudera realizá-los. lização das propostas republicanas. Tal bifurcação teria caracterizado, não apenas uma clivagem ideológica, mas a formatação de uma atitude política clara: Teófilo teria cedido às possibilidades de acesso ao poder institucional e teria, por isso, burocratizado em sentido tradicionalista e positivista a ação pública do PRP. Antero teria mantido a atitude crítica em relação à sociedade portuguesa que marcara os seus primeiros diagnósticos levados a público no Casino. 0 Partido Socialista, por sua vez, e diferente do que ocorrera na Espanha com os movimentos organizados de esquerda, não logrou grande influxo nos meios populares. Rui Ramos², por sua vez, destaca a importância de Teófilo como o "pai da pátria" na medida exata das suas preocupações em "organizar as forças vivas e a opinião pública e preparar uma ressurreição nacional"23 e dos seus esforços para reconstruir a memória nacional e, dessa forma, a identidade coletiva tão afetada pelo século das lutas liberais e das perdas coloniais em Portugal.

\section{A geração de 1870 e o Brasil.}

0 estudo do trânsito das idéias da geração portuguesa de 70 para o Brasil exige, a princípio, uma definição cronológica: optei por estudar o debate coevo entre intelectuais do Brasil e de Portugal. Beatriz Berrini24 sugere, a partir de estudo epistolográfico, o diálogo entre a geração portuguesa de 70 (nela destacados Ramalho Ortigão, Conde de Ficalho, Antero de Quental, Eça de Queiroz, Oliveira Martins, Batalha Reis, Guerra Junqueiro) e a brasileira (nela destacados Machado de Assis, Araripe Júnior, Joaquim Nabuco, Rui Barbosa, Sílvio Romero, Aluísio de Azevedo, Olavo Bilac, José Verissimo, Capistrano de Abreu, Euclides da Cunha, Eduardo Prado). Das cartas que a autora reuniu em seu livro destacam-se os temas do significado da missão dos homens de cultura nos processos modernizadores e/ou regeneradores, das suas intervenções no espaço público por meio dos periódicos e das suas preocupações com a importância da educação das camadas populares. A autora, a partir da leitura das cartas que inventariou com cuidado, afirma a existência de uma única geração de 70 luso-brasileira ou brasileiro-lusa. A idéia parece interessante e, sem dúvida, esclarece as intenções recíprocas expostas na epistolografia sumariada e reproduzida após transcrição cuidadosa em seu livro. Cabe, porém, inventariar diferenças e, mesmo, rediscutir o conceito de "geração" estabelecendo os conteúdos da intervenção pública pretendida e os ecos que foram capazes de suscitar ou não. Os conteúdos da modernização, por exemplo, não são unívocos. Antero de Quental aliava à idéia republicana o ideal socialista e, neste sentido, a modernização não poderia ser pensada sem as teses igualitárias que tiveram sua primavera em 1848. Teófilo Braga, por sua vez, marcado pelos textos positivistas, propunha uma modernização de cunho especificamente político-institucional: bastaria a substituição do regime monárquico pelo republicano e a reorganização partidário-eleitoral da vida pública, com vistas ao reerguimento do Império na África, para efetivar uma modernização que, no seu entender, era a fundamental.

Da geração portuguesa de 70 muito se afirma, segundo diagnóstico dos seus próprios integrantes durante a década de 90 do século XIX, ter sido "vencida pela vida". ${ }^{25}$ Sua presença nos debates da virada do século XIX para XX, nas críticas à Regeneração fontista e nos reflexos periodísticos e populares pós Ultimatum, assim como o peso do seu diagnóstico da decadência na historiografia portuguesa é, no entanto, inegável. 0 que os intelectuais e políticos do período aqui estudado descobriram foi a impor- 
Rui RAMOS, "0 fim do século", ob. Cit., p. 66.

27

Entre os autores recentes que discutem as condições de modernização e as possibilidades industriais portuguesas dialogando com as teses que apontam a decadência e/ou atraso da nação, cabe destacar Jorge PEDREIRA, Estrutura industrial e mercado colonial - Portugal e Brasil (1780-1830), Lisboa: Difel, 1994; e Os homens de negócio da praça de Lisboa de Pombal ao vintismo (1755-1822) Diferenciação, reprodução e identificação de um grupo social, 1995, tese de doutorado, exemplar xerocado (em preparo para publicação). No primeiro texto citado, à Introdução (p. 1011), o autor afirma: "Sucessivamente glosado e comentado, assumindo formas diferenciadas, adquirindo fisionomias diversas consoante os tempos, transfigurando-se através de sucessivas apropriações e manipulações, ao sabor dos interesses e das circunstâncias, o mito da decadência converteu-se ao longo de séculos num utensílio mental particularmente eficaz para transcrever em termos simbólicos as representações do destino nacional."

28

Teófilo BRAGA, Soluções positivas da política portuguesa, ob. Cit.

29

Ângela de Castro GOMES, História, historiadores, R.J.: FGV, 1999, pp. 48-49.

30

José-Augusto FRANÇA, Rafael Bordalo Pinheiro - 0 português tal e qual, Lisboa: Livraria Bertrand, 1980. Ramalho ORTIGÃO, "A arte satírica - Rafael Bordalo Pinheiro e o António Maria, a caricatura, seu valor artistico e seu valor histórico", In: As Farpas IX - 0 movimento literário e artístico, Lisboa: Clássica Editora, 1990, p. 121-150. Fialho D'ALMEIDA, "Raphael Bordalo Pinheiro", In: $\dot{A}$ Esquina (jornal d'um vagabundo, Lisboa: Clássica Editora, 1919, pp. 209-246.

31

Agradeço aos funcionários do IEB/USP a gentileza e a presteza na digitalização dessa edição fac-similar. tância da arte para "dar expressão à nação". 26 Mesmo os mais recentes historiadores, com propostas de análise, que condenam as teses da decadência como mitos construídos pelos autores do XIX peninsular reportam-se a Antero, Oliveira Martins e Herculano - este visto como antecedente das teses casinistas de $1871 .{ }^{27}$

Traço comum entre as gerações portuguesa e brasileira de 70 é o fato de participarem ativamente dos debates dos anos 90: no caso português tratava-se de enfrentar os efeitos do Ultimatum inglês de 1890 e pensar a viabilidade da República como substitutivo da Monarquia que, no entender especialmente de Teófilo Braga28, fora responsável pela "humilhação"; e, no caso brasileiro, tratava-se de pensar a organização da República que então se estabelecia, de saber que nação poderia vicejar após os emblemáticos 1888 e 1889. Segundo Ângela de Castro Gomes o jornalista José do Patrocínio pertencia ao grupo que se reunia em torno da Revista Brasileira e que

"foi o núcleo organizacional do grupo de intelectuais que, no início da estabilização política da República - em 1898 - decide criar a ABL. Feitas a Abolição e a República, e ultrapassados os anos entrópicos do militarismo e do jacobinismo, tratava-se de rearticular o campo intelectual em novas bases, mais afastadas dos engajamentos politicos e das questões culturais que assolaram a décadas de 70 e 80 do século passado. A segunda metade dos anos 1890 inaugurava um outro tempo, não sendo casual o sucesso do projeto intelectual que orientou o grupo da revista. Tratava-se de fundar uma associação - no conhecido modelo das academias --, cujo objetivo precípuo seria afirmar 'profissionalmente' o intelectual, ' afastando-o' da política (a dimensão partidária é clara) e propiciando a valorização de 'um ponto de vista realista', isto é, mais 'neutro' e portanto mais competente."29

Compunham o grupo, segundo a autora, Machado de Assis (como figura exponencial), Araripe Jr., Rui Barbosa, Lúcio de Mendonça, Coelho Neto, Medeiros de Albuquerque, Graça Aranha, e os historiadores Eduardo Prado, Oliveira Lima, Joaquim Nabuco, barão do Rio Branco, João Ribeiro e visconde de Taunay. Observe-se que alguns dos nomes coincidem com aqueles citados por Beatriz Berrini como pertencentes à geração que ela chama de 70 brasileira. Destaco José do Patrocínio porque ele participou da edição de $O$ Besouro junto com Rafael Bordalo Pinheiro na então capital do Império. ${ }^{30}$

O Besouro foi uma folha hebdomadária editada no Brasil por Rafael Bordalo Pinheiro (1846-1905) quando este caricaturista português, participante ativo dos debates da geração portuguesa de 70, esteve no Brasil entre os anos de 1875 e 1879. Trata-se de um periódico semanal, cuja edição fac-similar está disponível no IEB/USP31, que circulou entre abril de 1878 e março de 1879 e que teve ativa participação de José do Patrocínio, de quem Bordalo foi amigo, na editoria e execução diária. 0 estudo do periódico permite mapear as sociabilidades entre homens de cultura do Brasil e de Portugal nos anos 70 do século XIX e apontar conteúdos comuns que marcam a reflexão sobre as "possibilidades da política" no mundo ibérico. No debate da geração de 70 portuguesa, marcado pela Conferência de Antero de Quental no Casino Lisbonense, a noção de uma "decadência portuguesa", que inviabilizava a inserção do país no mundo moderno transpirenaico, e a urgência de equacionar os termos da regeneração possivel, colocava no centro das discussões o tema do significado 
dos impérios construídos pelos países ibéricos e sua inevitável herança. $\mathrm{Na}$ rotina semanal de "0 Besouro" a escravidão, o sistema monárquico, com os seus vícios políticos e suas deficiências sociais, assim como a "pobreza cultural do povo", aparecem como sintomas de uma longa história construída "às avessas". É possivel encontrar nas suas páginas discussões sobre a presença e a participação popular nos espaços públicos de negociação e ação política, num momento em que o periodismo brasílico era marcado pelo tema da escravidão, além de pensar o lugar dos "rotinizadores" na composição de uma vivência geracional. Temas sociais como a grande seca do Ceará de 1878 e temas políticos nos quais os lugares do parlamento eram preenchidos em eleições pouco representativas, ou ainda o Congresso Agrícola de 1878, despontam das suas páginas em textos literários, jornalisticos e, especialmente, nas caricaturas de Bordalo e nas "alfinetadas" de Patrocínio em forma de "zuns-zuns". Bordalo e Patrocínio são considerados aqui rotinizadores e publicistas do debate ibérico, em Portugal e no Brasil, atuando juntos na Corte brasílica em um momento no qual desenvolve-se a imprensa e a esfera pública urbana ganha novas dimensões. Em seções como Economia Política, na qual comentavam-se as ações governamentais ou as possibilidades de modernização do país nesta área, Zuns-zuns, na qual se inseriam pequenos comentários sobre cotidiano e politica na Corte e no país, Esboços parlamentares, na qual deputados e senadores eram caricaturados segundo suas ações ou ausências, Palcos e Bastidores, na qual eram comentadas novas montagens e/ou apresentações de Teatro e Ballet, é possivel mapear os conteúdos principais do debate aqui sumariado.

No folheto distribuido provavelmente em fevereiro (data da assinatura de Bordalo para a caricatura que se vê no verso do folheto) pode-se ler: "O Besouro - Folha ilustrada humorística e satírica - Publicação hebdomadária no Rio de Janeiro a começar em 6 de abril de 1878. Escritório da redação; 130, rua do ouvidor, 1. andar." Segue-Ihe, em outra página, caricatura de Bordalo com um homem gordo deitado no chão com uma espécie de calendário que o rodeia apontando caracteristicas de cada mês do ano (junho como mês teatral, janeiro como mês ministerial, maio como mês do "fallatorio, quando canta o sabiá", etc.). Entre os redatores e colaboradores encontravam-se: Henrique Chaves, José do Patrocínio, Dermeval da Fonseca, Luiz de Andrade, Lino de Assumpção, Alfredo Camarate, Simão da Motta, Thomaz Alves Filho, Arthur Barreiros, Arthur Azevedo, Alberto de Oliveira, Dr. Ferreira de Araújo, Mário, Filinto de Almeida, Fontoura Xavier, Generino dos Santos, Lucio de Mendonça, Guerra Junqueiro, Julio Xavier, Affonso Celso Junior.

Para a edição que reunia todos os números do Besouro, editada pela "Typ. De G. Leuzinger \& Filhos, rua do Ouvidor, 31, Rio de Janeiro", podia-se ler, a título de Prefácio, o seguinte texto (cuja grafia mantive sem correções):

"Ser pontual.

Coisa difficil!

Ter espirito.

Coisa mais difficil ainda!

To be or not to be.

Circulo de ferro.

Zero e o Infinito.

Zero é representado por este sinal: 0 .

O infinito por este: (o autor colocou um 8 deitado). 
Zero é metade do Infinito.

0 Infinito é quase Zero.

Logo

$$
0+\text { oito deitado }=1
$$

Dahi o Besouro.

É uma formila.

Uma formula algébrica.

Clara.

Positiva.

Brutal.

O Besouro tem uma legião de inimigos: os Vícios.

E só uma arma; a Gargalhada.

No emtanto que de mortos!

Malferidos!

Contusos

Escoriados!

Amarrados ao próprio cadáver!

E a Gargalhada, a larga, a retumbante, a victoriosa Gargalhada, cada dia faz-se mais victoriosa, mais retumbante, mais larga.

Excede a funda de David.

A queixada de Sansão.

A espingarda de agulha.

0 canhão Krupp.

A Gargalhada é a Revolução.

Conclusão:

Prefacio compõe-se de duas palavras latinas:

Pré, prep., antes.

Facio, is, feci, factum, ere, v., fazer.

Isto é:

Feito antes.

A estas meias-palavras pois, dá-se-Ihe o nome de prefacio

Por uma razão.

Foram escriptas depois.

Temos dicto tudo.

Ou antes:

Não temos dicto nada.

E é quanto basta.

O Besouro

31 de dezembro, 1878, debaixo de 101 centigrados."

Também no primeiro número encontra-se uma caricatura de Bordalo na qual se vê besouros a voar em torno de uma espécie de construção vertical com forma de um homem na parte inferior e de uma fonte iluminada com pequenas esculturas de rostos masculinos na parte superior. Ao redor da construção homens observam o movimento dos besouros e á direita do desenho lê-se: "0 Besouro volteará sempre ao redor da luz brilhante de todos os acontecimentos e de todos os casos, sem se queimar."

Em um artigo intitulado 0 Besouro, entre as páginas 2 e 3 do número inicial de 6 de abril de 1878, José do Patrocínio contava a história das conversas para definir o nome do novo periódico. Foi exatamente a presença de um besouro a zumbir quando discutiam e/ou dormiam Bordalo, 
32

O Besouro, 06 de Julho de 1878, disponivel no Museu Rafael Bordalo Pinheiro (digitalizado), Lisboa/Portugal e no IEB/USP/Brasil (impresso). Há ainda muito que pesquisar sobre a viagem de Bordalo ao Brasil e seu retorno a Portugal após o acirramento das suas divergências com Ângelo Agostini. 0 afastamento de José do Patrocínio da editoria de $O$ Besouro, exatamente na esteira desta polêmica, sem dúvida muito contribuiu para as dificuldades do periódico depois de Dezembro de 1878. O Besouro será objeto de outro ensaio que pormenoriza conteúdos e temas e a inserção do periódico no debate braślico da década de 70 do Oitocentos.
Patrocínio, Simão da Motta e Chaves que inspirou o batismo do novo periódico. Afirmava Patrocínio no artigo citado:

"Somos todo pacatos, amigos da Constituição e dos plats du jour; apreciadre sympathicos do programma da economia e do programma da Praça de Touros, leaes ao throno e ás damas que nos escrevem o seu lamartinismo. (...) Como o insecto, de que tomamos o nome, em vôos travessos no recinto em que nós embuçávamos em madorra alvar a nossa impotencia; havemos de roçar os quadros - a arte; as estantes - a litteratura; os tapetes - a política, os moveis - a industria e o commercio."

Tal intenção de intervenção verifica-se nos assuntos tratados: entre textos dos autores citados como colaboradores e caricaturas de Bordalo aparecem críticas ao "homem-peixe da política, que come, bebe, joga e fuma dentro e fora d'agua" 32 , referindo-se provavelmente ao conjunto de políticos em geral, a titubear entre conservadorismo e liberalismo:

"Vêem os Senhores que perícia? Tanta água, nem assim está mais limpo. Com verdade, fóra ou dentro da água o homem-peixe está muito bem porque tem talento e muito espírito. Isso não acontece aos outros que, quando estão fóra da água, são como os carangueijos, andam só para trás."

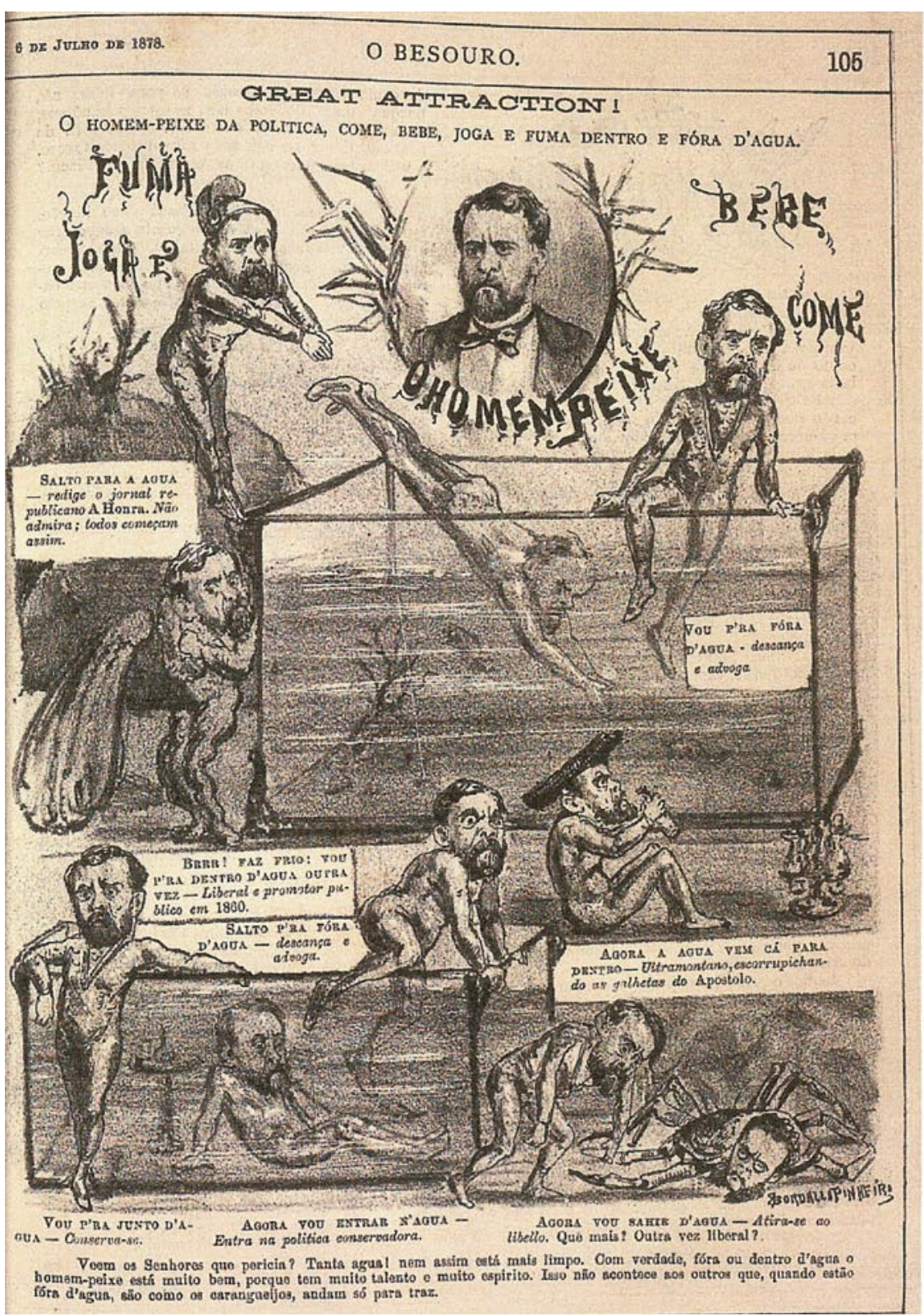


Sérgio Campos MATOS, "O Brasil na historiografia portuguesa oitocentista", In: Convergência Lusíada, 18, vol. 2, Rio de Janeiro: real gabinete de Leitura, 2001, pp. 319-332.

\section{4}

Cabe destacar estudos de outras sociabilidades, como aquelas entre Eça de Queiroz, Machado de Assis e Eduardo Prado, indicadoras do debate que chamo aqui de Atlântico: José Leonardo do NASCIMENTO, O debate em torno do Primo Basílio na imprensa brasileira: Machado de Assis, Eça de Queirós, et alli., exemplar policopiado, e que será objeto de debate junto ao grupo de estudos "Migrações. Movimentação de pessoas, idéias, instituições e riquezas no mundo de lingua portuguesa: História e Historiografia (séculos XIX e XX)", formado junto à Cátedra Jaime Cortesão; a correspondência publicada por Beatriz BERRINI, op.cit., e, ainda Cartas inéditas de Eça de Queiroz, Lisboa: 0 Jornal, 1987; e, por último, a pesquisa de Maria Filomena MÓNICA, embora dê pouca atenção para essas relações tão bem estudadas por José Leonardo Nascimento, indica caminhos que a autora não trilhou e que procuramos seguir. Cf., Maria Filomena MÓNICA, Eça - 0 regresso impossivel, Lisboa: ICS, 2001.

35

Tais nexos são sugeridos pela tradição historiográfica à qual pertencem os trabaIhos de Quentin SKINNER, Visões da politica, Miraflores: Difel, 2002; e J. G. A. POCOCK, Linguagens do ideário político, S.P.: Edusp, 2003.

\section{6}

As observações que faço sobre o conceito de geração muito devem à gentileza do Professor Sérgio Campos Matos, da Universidade de Lisboa, que leu com antecedência o texto Jaime Cortesão e Paulo Prado: as afinidades eletivas na leitura da memória do Império, ainda em preparo para publicação.

37

Cabe destacar Fernando CATROGA, $O$ Republicanismo em Portugal - Da formação ao 5 de Outubro de 1910, ob. Cit.; Rui RAMOS, A segunda fundação, vol 6 de José MATTOSO (org), História de Portugal, ob. Cit.; Sérgio Campos MATOS, Historiografia e memória nacional no Portugal do século XIX, ob. Cit.; ; Antonio Pedro PITA, "Os intelectuais e democracia ou a democracia dos intelectuais", In: Maria Emilia PRADO (org.), Tradição e Modernidade no Mundo Ibero-Americano, R.J.: CNPQ, 2004, pp. 11-22.

\section{8}

Ver Angela de Castro GOMES, História, historiadores, ob. Cit., e Essa gente do Rio ... Modernismo e nacionalismo, R. J.: FGV, 1999; Sérgio MICELI, , S. Intelectuais à brasileira. S. P., Cia das Letras, 2001 e Imagens negociadas, S. P.: Cia das Letras, 1996. Cabe destacar uma importante diferença de abordagem entre os dois autores. A sugestão de Castro Gomes sobre a importância de relevar o que foram as intenções dos autores estudados parece bem mais interessante do que a sugestão de Miceli acerca da aproximação dos intelectuais em termos apenas de cooptação consentida.
Impossivel não lembrar da caricatura do Zé Povinho na História que, criado por Bordalo em 1875, caracterizava-se por nunca se levantar sem que se deitasse novamente. Herdeira da Carta Constitucional e do liberalismo que se estabeleceu após o setembrismo, a figura do Zé Povinho em Portugal, assim como a deste Homem-peixe da política no Brasil, permitem associar o liberalismo à passividade das camadas populares e compreender os conteúdos desta proposta política em nações com níveis de alfabetização e participação popular nas questões públicas flagrantemente atrasados. ${ }^{33}$

Nos exemplos colocados encontram-se esboços de sociabilidade entre intelectuais brasileiros e portugueses (Bordalo e Patrocínio) e conteúdos (viabilidade do processo democrático no mundo ibérico) que permitem indicar os temas mais significativos da intervenção pública dos homens de cultura da geração de 70 portuguesa e suas relações com a geração de 70 brasileira, indagando da continuidade da sua ação nos anos 90 e no início do século XX. Sociabilidades marcadas pela definição de um espaço público e de uma produção periodística e que apontam profícuas "relações atlânticas". ${ }^{34}$

\section{Entre autores, idéias e gerações.}

A busca dos nexos entre obra, trajetória e contexto 35 , visto este como espaço público plural e conflituoso no qual se enfrentam propostas e leituras de mundo, é, sem dúvida, um grande desafio no âmbito de uma pesquisa que precisa enfrentar o difícil conceito de geração ${ }^{36}$. Sem dúvida, a pretensão de unidade de ação ou de idéias que pode indicar tal conceito não se verifica em nenhum dos grupos de intelectuais aqui citados. Entre os homens de cultura do chamado setenta português, brasileiro ou espanhol, assim como entre aqueles do 1898 espanhol, ou aqueles que, adentrando o século XX, formaram a Renascença e a Seara Nova em Portugal e organizaram a Semana de Arte Moderna no Brasil, há muito mais ecletismo de leituras, interpretações e proposições do que congruências políticas e/ou artisticas.

A bibliografia mais recente sobre "história intelectual" em Portugal37 e Brasil 38 com a qual tenho dialogado na condução desta pesquisa tem forte influxo do debate francês que é, por sua vez, marcado, em suas linhas principais, pelas noções de "campo intelectual" e "habitus" desenvolvidas por Pierre Bourdieu. 39 Advogando uma investigação para história da literatura e da arte que escapasse aos limites de uma biografia intelectual, Bourdieu sugeriu a inserção do autor estudado e da sua obra "no interior do campo ideológico de que faz parte", em uma palavra, caberia ao pesquisador esquadrinhar as estratégias de ação (os conflitos e as disputas pelo espaço e pelos lugares de institucionalização) entre grupos situados no interior do campo intelectual em sua dimensão de campo político de poder diretamente relacionado com as elites dirigentes. É no seio dessas relações conflituosas que se estabelecem "habitus" estruturadores das práticas caracteristicas dos agentes em questão.

$\mathrm{Na}$ esteira dessas teses e da retomada da história política passou-se a pensar no intelectual como produtor de bens simbólicos que é, por isso, ator político 40 , e que atua na formação e divulgação da cultura política de certa época. Para o estudo de história das idéias nessa lógica havia que definir textos, suportes e autores e apontar sua relevância e significado no conjunto da produção de dado periodo. É, neste sentido, interessante a sugestão de estudar autores ditos secundários e "modestos objetos culturais" mas que se constituem, do ponto de vista da época em que atuam ou 
Pierre BOURDIEU, A economia das trocas simbólicas, S.P.: Perspectiva, 2005.

\section{0}

Jean-François SIRINELLI, "Os intelectuais", In: René RÉMOND, Por uma história política, R. J.: FGV, 2003, pp. 231-270.

\section{1}

Michel WINOCK, "As idéias políticas", In: René RÉMOND, ob. Cit., p. 281. Ver também do mesmo autor, 0 século dos intelectuais, R. J.: Bertrand Brasil, 2000.

\section{2}

CANDIDO, A. "A revolução de 30 e a cultura", In: Novos Estudos Cebrap, vol. 02, n. ${ }^{\circ} 04$, pp. 27-36, abril de 1984 e Formação da Literatura brasileira, B. H.: Itatiaia, 1997, 2 volumes.

\section{3}

Roger CHARTIER, "História intelectual e história das mentalidades", In: Á beira da falésia - $A$ História entre certezas e inquietudes, Porto Alegre: Editora da UFRS, 2002, pp. 23-60.

\section{4}

Cf.Jean-François SIRINELLI, "Os intelectuais", ob. Cit.

\section{5}

Ressalvo a junção de duas noções pertencentes a duas tradições historiográficas: a noção de representação está vinculada à tradição francesa à qual me referi acima e se reporta às representações coletivas que estariam emblemadas nos discursos das elites intelectuais no que diz respeito a este projeto. Já a noção de visão de mundo, desenvolvida, por exemplo, por Lucien Goldmann, reporta-se às formulações de Georg Lukács interessado em desvendar os complexos caminhos por meio dos quais a obrade-arte encontra lugar no social inferindo-se e reportando-s a ele ao mesmo tempo. Creio que a noção de "visão de mundo" articula melhor os nexos entre idéias e sociedade e que traz em si, como um dos seus efetivos conteúdos, as construções/representações da nação. Cf. Georg LUKÁCS, Ensaios sobre Literatura. R.J.: Civilização Brasileira, 1965 e Nueva Historia de la literatura alemana. Buenos Aires: Editorial la Pleyade, 1971.

\section{6}

J. W. GOETHE, Las afinidades electivas, Barcelona: Icaria, 1967. Walter BENJAMIN, "Les Affinités électives de Goethe", In: Oeuvres, Tomo I, Paris: Gallimard, 2000, p. 274-395. LOWY, M. "Sobre o conceito de afinidade eletiva", In: Redenção e utopia, S. P.: Cia das Letras, 1989. são publicados, "poderosos fatores de impregnação ideológica"41 e, acima de tudo, para usar um termo de Antonio Candido42, autores ou suportes responsáveis pelo estabelecimento de certa "rotina" de pensamento. 0 risco das abordagens quantitativas de certa história cultural que releva o rotineiro apenas a título de enumeração como se esta fosse capaz de apontar os conteúdos significantes para a compreensão dos pensamentos coletivos, ou mesmo do grupo de intelectuais que se pretende estudar, já foram apontados por Jean Ehrard e Roger Chartier 43 e se localizam a longa distância das intenções de Antonio Candido.

Mas há nas teses tributárias das idéias de Pierre Bourdieu uma questão para discutir em relação ao estudo das interseções entre itinerário, geração e sociabilidade. Cabe ao historiador das idéias observar estratégias de ação individual e grupal e o "habitus" que configura tais estratégias e aponta projetos efetivamente veiculados e/ou abortados. A geração, nesta lógica, permite encontrar filiações, negociações e conflitos, não apenas em função das faixas etárias envolvidas, mas, principalmente do ponto de vista da percepção de uma temporalidade própria aos participantes nos debates ditos geracionais. ${ }^{44}$ Ocorre, no entanto, que tal perspectiva pode enclausurar a interpretação possivel do historiador no âmbito dos grupos direta ou indiretamente envolvidos nos debates e nas disputas politicas que buscam institucionalizar os posicionamentos defendidos no seio do campo intelectual em relação ao campo político propriamente dito. 0 que quero registrar são minhas dúvidas acerca da operacionalidade da noção de "campo", acredito que ela aponta para certa autonomização do que seria o campo intelectual perdendo-se o nexo com o contexto, posto que este não me perece possa ser resumido ao intelectual.

Talvez seja interessante pensar na história intelectual dentro das possibilidades de estudo colocadas pela História das idéias que busca inventariar e interpretar "visões de mundo", apontando estas para representações construídas da nação no âmbito das propostas de modernização colocadas na virada do século XIX para o XX no mundo ibérico. Para tanto, repensar o contexto para além das sociabilidades e estratégias internas aos campos "intelectual" e "político" em sentido estrito tem sido fundamental. 0 que tem especialmente inspirado este trabalho é a procura dos nexos entre produção das idéias e portadores sociais na medida em que o periodo estudado assistiu a uma enorme profusão de meios e suportes públicos (periódicos, cátedras, grêmios, associações políticas diversas, etc.) que podiam ancorar as aspirações dos homens de cultura na divulgação de suas representações da nação/visões de mundo 45 e, dessa forma, conduzir a sua utopia de superar o atraso/decadência indicando às massas, por meio da construção da memória histórica, o caminho para a modernização. É neste sentido que a noção de "afinidades eletivas"46 tem se mostrado interessante para compreender os nexos citados, as visões de mundo e as linhas de continuidade existentes entre os grupos que estudo aqui.

Na sua biografia sobre um dos principais propagandistas da Abolição dos escravos no Brasil, José do Patrocínio, afirma Roberto Magalhães Jr.:

"Entrou para o jornal liberal 'A Reforma' como conferente de revisão. A essa altura (1874), a folha republicana em que publicara seus primeiros versos ('A República') já havia desaparecido, depois de atacada pela polícia, quando enfeitara a fachada e colocara placares, anunciando a queda da monarquia espanhola e a proclamação da efêmera república de Emilio 
47

R. MAGALHÃES Jr., A vida turbulenta de José do Patrocínio, São Paulo: Lisa; Rio de Janeiro: INL, 1972, p. 23.

\section{8}

Antonio CANDID0, "Radicalismo", In: Vários escritos, São Paulo: Duas Cidades, 1995, p. 265.

49

José Fanelli era bakuninista italiano e membro da Primeira Internacional, havia chegado à Espanha em meados de 1868 com a missão de criar uma seção espanhola da Internacional que fizesse frente à orientação dominante da Internacional liderada por Karl Marx e F. Engels.

50

"La solidaridad", n. 17, 07 de maio de 1870, citado por Antonio ELORZA e Carmen L. ALONSO, Arcaísmo y modernidad - Pensamiento politico en España, siglos XIX-XX, Madri: Temi, 1989, p.84.

51

"La Defensa de la sociedad", citado por Antonio ELORZA e Carmen L. ALONSO, Arcaísmo y modernidad - Pensamiento político en España, siglos XIX-XX, Madri: Temi, 1989, p. 85.

52

Rafael Bordalo PINHEIRO, O Besouro, 18 de Abril de 1878, disponivel no Museu Rafael Bordalo Pinheiro de Lisboa/Portugal (digitalizado) e no IEB/USP/Brasil (impresso).

53

Eça de QUEIROZ e Ramalho ORTIGÃO, "Estado de alma português", 1873, In As Farpas Chronica mensal de política, das letras e dos costumes, Lisboa: Typografia Universal, 18711883. Retirado Da Biblioteca Nacional Digital de Portugal.
Castelar. Pouco antes de ser empastelada pelos agentes de polícia, disfarçados em populares leais à monarquia, 'A República' vinha publicando, em folhetins, 'As Farpas', de Eça de Queiroz e Ramalho Ortigão. (...) E iriam suscitar, no Brasil, toda uma série de publicações idênticas. A primeira destas seria 'Os Ferrões', assinados por Notus Ferrão e Eurus Ferrão. 0 primeiro de tais pseudônimos era o de José do Patrocínio e o segundo o de Dermeval Fonseca, seu companheiro de aventura jornalística que movimentou o Rio de Janeiro de 1875. " 47

0 debate que salta das páginas do periodismo ibérico nos anos 70 e 80 permite esquadrinhar melhor o contexto que tento sumariar aqui e afirmar certa afinidade eletiva no que diz respeito tanto aos temas e problemas enfrentados pelos homens de cultura dos anos 70 e 80 na Espanha, em Portugal e no Brasil, como ao tom "radical" do conjunto de suas idéias e atitudes que formavam um "contrapeso ao movimento conservador"48 predominante.

Na pena de anarquistas espanhóis, organizados em torno do periódico internacionalista de Madri "Solidaridad"49:

"Decidido a defender en toda su pureza los salvadores princípios de la Asociación Internacionl de los Trabajadores, nunca transigirá con ninguno de esos paliativos propuestos por la clase media o por sus oficiosos defensores, para adormecer al trabajador y separarle de la senda que ha de conducirle a la realización de su completa emancipación econômica y social." 50

Na pena dos contra-revolucionários quando, refletindo os ecos da Comuna de Paris e o crescimento do internacionalismo nas espanhas, fundaram o periódico "La defensa de la sociedad":

"(...) la Revista es, por su índole, y en esto se distingue de las demás, una publicación de doctrinas de interes pemanente (...). para complemento de ella, y tan pronto como sus recursos lo permitan, se darán publicaciones aparte, unas escojidas para todas las clases ilustradas y para la juventud estudiosa, que bebe en las malas fuentes el veneno que daña, y otras populares para la masa de la población de ciudades, pueblos, talleres y aldeãs (...)." 51

$\mathrm{Na}$ ironia da caricatura de Bordalo refletindo o debate sobre a publicação de 0 Primo Basilio de Eça de Queiroz no Brasil: a madame apresenta o "primo Quincas que volta de Paris", bem arrumado e cheio de alegrias e o comendador (à parte): "Mau.... mau."52

Ou em "As Farpas - Chronica mensal de política, artes e dos costumes" na qual Ramalho Ortigão e Eça de Queiroz manifestavam forte pessimismo histórico:

"Temos do constitucionalismo - esgotado-tudo o que elle tinha da mau na lia: a nobilitação dos parvenus, a falsa aristocracia, a falsa grandeza, a falsa virtude, o falso talento, o funccionalismo exuberante, a arrogância burgueza, o reinado da usura, a ruína do trabalho, a decadência da arte (...)." 53 
54

IDEM, 1882

55

Sobre Portugal veja-se Rui RAMOS, $A$ segunda fundação, op. Cit., e José TENGARRINHA, História da Imprensa periódica em Portugal, Lisboa: Portugália, 1966. Sobre o Brasil vejase Sérgio Buarque de HOLANDA, O Brasil monárquico - Do Império à República, São Paulo: Difel, 1983; Nelson Werneck, SODRÉ, História da imprensa no Brasil, Rio de Janeiro: Civilização Brasileira, 1966.
"Na grande maioria dos círculos eleitorais do país, continente e ilhas, todo eleitor que não vende simples e chamante o seu voto por dinheiro, vende-o por serviços, por bondades, ou por favores pessoais, ao pároco, ao escrivão da fazenda que cobra a décima, ou ao agente do recrutamento que manda prender para soldado. À pressão oficial acresce ainda a pressão do compadrio local. Na ilha da madeira, cujos interesses são neste momento representados no Parlamento pelo deputado Manuel Arriaga, o compadrio tem sobre a livre expressão da vontade do eleitor uma influência ainda mais despótica do que a da própria autoridade constituída." 54

Em todos esses exemplos destacam-se conteúdos de radicalismo. É neste momento de influxo do periodismo, compreendido aqui como de corte radical que José do Patrocínio, envolvido nas campanhas abolicionista e republicana, em 1878, reuniu-se a Rafael Bordalo Pinheiro, português que se mudara recentemente para o Brasil e que emprestara sua arguta pena ao periódico '0 Mosquito', para fundar o hebdomadário '0 Besouro'.

Juntos, entre os meses de Abril e Dezembro de 1878, por meio das páginas deste hebdomadário, Patrocínio e Bordalo enfrentariam questões sociais e políticas do Brasil em chave de compreensão ibérica: a escravidão que marcava o Brasil e exigia o urgente debate das formas de inserção dos negros livres na sociedade, a seca que assolou o estado do Ceará naquele ano, a ação política das elites econômicas tupiniquins e sua relação patrimonialista com o regime monárquico, entre outros. Estes eram conteúdos de uma crise cujas origens remontavam-se, no debate intelectual do setenta brasileiro, à história colonial. Tal diagnóstico, no entanto, aqui chegara pelo mesmo caminho que trouxera os primeiros colonizadores. Sociabilidades e "afinidades eletivas" entre homens de cultura e de imprensa no mundo ibérico? Sim. Bordalo e Patrocínio são rotinizadores e publicistas do debate ibérico, em Portugal e no Brasil, atuando juntos na Corte brasílica em um momento no qual se desenvolve a imprensa e a esfera pública urbana ganha novas dimensões ${ }^{55}$. Os periódicos, nesta época, deixam de ser apenas órgãos subvencionados pelas redes clientelares que marcavam a nomeação dos professores do tradicional Colégio Pedro II e de muitos outros cargos caros à manutenção da ordem imperial.

A pequena notícia que nos oferece Magalhães Jr. sobre a presença de José do Patrocínio no periodismo brasileiro decimonônico finisecular sugere, assim, uma interessante afinidade eletiva entre homens de cultura do Brasil e de Portugal. Marcados pela experiência republicana espanhola, pelo crescimento dos movimentos populares de orientação revolucionária e pela expansão imperialista, que trazia em si todo um desenvolvimento tecnológico e científico e desafiava o atraso a que viam suas respectivas nações reduzidas, esses letrados usaram do periódico e das cátedras como arma para divulgar suas teses e intervir nos espaços públicos. "As Farpas", "Os Ferrões", "O Besouro", "La Defensa de la Sociedad", "Solidaridad", são espaços de luta e de expressão de radicalismos nos anos 70 e 80 do século XIX. Mesmo conteúdos conservadores advogavam certa ação radical que se prestava à interpretação e sugestão revolucionária. 0 tom dos radicalismos que ecoavam deste periodismo invadirá o século XX e assumirá roupagens diferenciadas: será revolucionário na pena de Antero e será conservador e tradicionalista na pena de Teófilo Braga. Estendendo o argumento para autores que também enfrentaram o debate aqui sumariado no 
56

Valentim ALEXANDRE, Velho Brasil, novas Áfricas - Portugal e o Império (1808-1975), Porto: Afrontamento, 2000.

57

João de Andrade CORVO, Portugal na Europa e no mundo, Porto: Fronteira do Caos Editores, 2005. mundo ibérico: será conservador também na pena de José Ortega y Gasset, procurará o justo equilibrio com a defesa das liberdades públicas na ação de Manuel Azaña e na historiografia de Jaime Cortesão, será ambíguo na ação e na pena de Paulo Prado, e também na ação de José do Patrocínio e Eduardo Prado, politicamente distantes, mas talvez próximos na luta contra a República brasileira dita jacobina.

Em um dos casos específicos estudado aqui nas terras do Reino agora europeu, o do republicano fundador do PRP Teófilo Braga, a hipótese da modernização tinha como corolário a construção do Império na África. E então, e para finalizar, cabe indagar: quem poderiam ser os portadores sociais dos ideais republicanos divulgados pelo PRP nos seus centros de alfabetização e politização das camadas populares?

1890 é um ano fundamental para se tentar responder tal indagação, foi a partir do Ultimatum inglês, exigindo a retirada das expedições portuguesas que agiam entre as fronteiras de Angola e Moçambique na África do Centro-Sul, que se acirrou um movimento nacionalista que já vinha se manifestando desde as ações de Andrade Corvo como Ministro do Ultramar. 56 Este ministro pautou sua atitude frente à Inglaterra pela percepção da insuficiência dos capitais portugueses disponíveis mesmo após o fim do tráfico que, em tese, teria liberado capitais e energias para outras atividades. Na esteira das teses abolicionistas de Sá da Bandeira que buscavam modernizar a exploração colonial portuguesa, Andrade Corvo, nos anos 70 do XIX, imaginava abrir rotas de comércio no interior das áreas coloniais da África e, dessa forma, reconverter as atividades escravistas em atividades produtivas. Para tanto seriam necessários capitais e "gentes": os primeiros eram insuficientes e os segundos, quando disponíveis, preferiam o Brasil. Essas insuficiências é que explicam, segundo Andrade Corv057, a necessidade de aproximação com a Inglaterra: era preciso atrair capitais e "gentes" que fizessem produzir as colônias para converter a tributação sobre o comércio e a produção para os cofres públicos portugueses. Mas as Cortes, e principalmente o PRP, que então tinha baixíssima representação nelas, negavam-se a corroborar tais teses afirmando-as entreguistas e contrárias à vocação colonizadora e civilizadora de Portugal.

Essa corrente nacionalista fundamenta sua defesa do Império no próprio Liberalismo que se desenvolveu na Península: é um Liberalismo que implica mutuamente tradição e modernidade mesmo quando, na voz dos homens da geração de 70 , pretende-se socialista ou democrático. 0 termo "revolução" tem, neste sentido e desde o vintismo - e mesmo na reação espanhola à invasão de 1808, se quisermos estender o argumento --, um conteúdo de resgate do passado que the retira a possibilidade de apresentar-se como ruptura de fato, e que acaba por sacralizar o Império no debate das elites intelectuais, especialmente no discurso do PRP do qual Teófilo Braga era um dos principais representantes. A democracia, como a sonhava Teófilo, e que ele pretendeu instaurar quando se tornou presidente provisório da República que ajudara a fundar em 1910, não era a procedimental herdeira das Luzes que conhecemos, ou com a qual sonhamos, mas sim, como ele dizia, deveria ser orgânica.

Poderiam as elites econômicas vinculadas ao comércio colonial serem atores sociais para o projeto colonial africano? A leitura das fontes da época, como Sá da Bandeira e Andrade Corvo, e da historiografia aponta ausência de capitais nas mãos dos homens de negócio ou da burguesia comercial, como se queira usar um ou outro termo. Não creio que o 
0 debate sobre o imperialismo "não econômico" encontra-se nos seguintes textos: Valentim ALEXANDRE, Velho Brasil, novas Áfricas, op. Cit., Gervase CLARENCE-SMITH, O III Império português (1825-1975), Lisboa: Teorema, 1985. Pedro LAINS, Os progressos do atraso, Lisboa: ICS, 2003, João Pedro MARQUES, Os sons do silêncio: o Portugal do oitocentos e a Abolição do tráfico de escravos, Lisboa: ICS 1999.

\section{9}

Eça de QUEIROZ, A llustre casa de Ramires, S.P.: Martins Claret, 2002. Cf. também: Feliciano RAMOS, Eça de Queiroz e seus últimos valores, Lisboa: Revista de Ocidente, 1945.

\section{0}

João MEDINA, "A democracia frágil: a Primeira República portuguesa (1910-1926)", In: História de Portugal, Bauru: Edusc, S.P.: Unesp e PT: Instituto Camões, 2001, pp. 375-390.
Terceiro Império tenha sido "não econômico"58 como pretende parte da historiografia, mas seguramente a exploração da África oferecia menos ganhos econômicos do que supunham seus idealizadores e permite sugerir certa matriz ideológica cuja fonte é o Império da primeira modernidade. Os debates da geração de 70, que se estenderam pelos anos 80 e 90 do XIX, são testemunhos dos conflitos entre as possibilidades econômicas, colocadas por uma nação localizada na periferia do capitalismo contemporâneo de tintas imperialistas, e as representações da nação nos termos do binômio decadência/atraso que marcavam a visão de mundo dessas elites e dos portugueses. A trajetória do personagem de Eça de Queiroz, Gonçalo Mendes Ramires 59 , ilustra claramente o conflito: há interesse econômico na África, mas não há capital disponivel para efetivar e executar as tarefas e atividades colonizadoras que, acreditavam muitos, regenerariam a nação e a redimiriam do seu atraso. 0 imperialismo do XIX é essencialmente exportador de capitais, Portugal tinha dificuldades de abolir a escravidão exatamente pelas dificuldades em reconverter seus lucros em atividades produtivas que exigiriam maiores investimentos. Eça sabia disso, assim como Antero de Quental: esses dois autores perceberam a sobrevivência do Império como ideal, o interesse econômico que ele despertava e, ao mesmo tempo, a dificuldade de efetivar tal interesse por meio dos investimentos cabiveis.

A ausência de portadores sociais para o discurso republicano/colonialista explica, não apenas o isolamento do PRP após a proclamação da República 60 , mas o sonho de um Bismarck português que pudesse vertebrar a nação e regenerar o Império, sonho que não seduziu Antero de Quental, mas que foi caro a Teófilo Braga e a Fernando Pessoa e que explica o distanciamento da República para com o povo que ajudara a fundá-la acreditando ser essa a "revolução portuguesa" que colocaria Portugal nos trilhos da modernidade. 